\title{
Computational Modeling of Magnetic Properties and Glass Forming Ability of Bulk Amorphous Materials
}

\author{
M. Kabaer, H. Ovalioglu and I. KuCUK* \\ Physics Department, Faculty of Arts and Sciences, Uludag University, Gorukle Campus 16059, Bursa, Turkey \\ A model based on artificial neural network was designed for the simulation and estimation of glass forming \\ ability parameters and saturation magnetization and coercivity of bulk glassy alloys. Its performance is evaluated \\ by the influences of different kinds of alloys and elements on the glass forming ability and magnetic properties. \\ The values of glass forming ability parameters and saturation magnetization and coercivity values estimated by \\ artificial neural network agree well with the experimental values, indicating that the model is reliable and adequate.
}

PACS numbers: 64.70.pe, 84.35.+i, 75.50.Vv, 75.50.Kj

\section{Introduction}

Recently, there are many researches to fabricate bulk amorphous alloys in different systems, with different geometries and good magnetic characteristics for specific applications [1]. Studies focused on evaluating glass forming ability (GFA) benefit much from the determination of several thermal parameters such as glass transition temperature $\left(T_{\mathrm{g}}\right)$, crystallization temperature $\left(T_{x}\right)$, and melting (liquidus) temperature $\left(T_{l}\right)$. The reduced glass transition temperature $\left(T_{\mathrm{rg}}\right)$ criterion has proved to be generally applicable to all alloy systems [2]. Artificial neural networks (ANNs) have been applied in many areas $[3,4]$, because of these features.

In this paper, the GFA parameters $\left(T_{\mathrm{g}}, T_{x}\right.$ and $\left.T_{\mathrm{rg}}\right)$, saturation magnetization $\left(J_{\mathrm{s}}\right)$ and coercivity $\left(H_{\mathrm{c}}\right)$ are modelled using previously reported data of magnetic bulk glassy alloys.

\section{ANN applications to GFA of magnetic bulk glassy alloys}

A total of 95 input vectors were available in the training data set of experimental data [5-17] for 100 magnetic glassy alloys with different chemical compositions. A set of data was used for testing the network. Matlab ${ }^{T M}$ has been used for training the networks, giving the advantage of rapid network development through flexible choices of algorithms, output functions and other training parameters, thereby enhancing accuracy. A multilayered neural network, which has 20 input neurons, 5 output neurons, 10 neurons of hidden layer and full connectivity between neurons, was developed. The number of hidden layers and the number of neurons in hidden layer were determined through trial and error to be optimal. The input parameters were atomic percent of elements $(\mathrm{Fe}, \mathrm{Co}, \mathrm{Nb}$, B, Zr, Mo, W, Si, Ni, Ta, Ti, Cr, Y, Cu, Al, Hf, P, $\mathrm{C}, \mathrm{Ga}$ ) of magnetic bulk glassy alloys and densities of alloys $(\rho)$. The output parameters were $T_{\mathrm{g}}, T_{x}, T_{\mathrm{rg}}$, and $J_{\mathrm{s}}$

* corresponding author; e-mail: ikucuk@uludag.edu.tr and $H_{\mathrm{c}}$. The network has been trained by using the genetic and the Levenberg-Marquardt algorithm with the hyperbolic tangent transfer function in hidden layer, sigmoid transfer function in output layer and 1000 epochs. After the network was trained, the mean squared error was found to be 0.0015 . When the network has been tested with training data set, the linear correlation coefficient was found to be on average $99 \%$ for the $T_{\mathrm{g}}, T_{x}$, $T_{\mathrm{rg}}, J_{\mathrm{s}}$ and $H_{\mathrm{c}}$.

\section{Results and discussion}

Table compares predictions and previously reported experimental data in the literature of the GFA parameters and magnetic values for 7 magnetic glassy alloys. These alloys are within the training data set. The average absolute difference for the predictions and experimental data is about $2 \%$. This shows that the ANN has an acceptable prediction capability for the alloys within the training data.

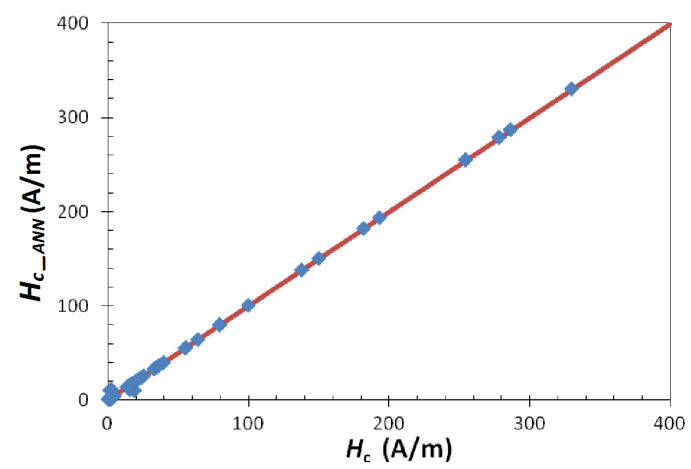

Fig. 1. Plot of the measured $H_{\mathrm{c}}$ versus the network outputs.

Figure 1 shows the $H_{\mathrm{c}}$ values versus the network outputs for all training data set. The diagonal line in this graph shows perfect match between measurement and network output. Figure 2 also compares between prediction of ANN and experimental $J_{\mathrm{S}}$ and $H_{\mathrm{c}}$ values for $\mathrm{Fe}_{68.2} \mathrm{C}_{7.0} \mathrm{Si}_{3.3} \mathrm{~B}_{5.5} \mathrm{P}_{8.7} \mathrm{Cr}_{2.3} \mathrm{Al}_{2.0} \mathrm{Co}_{3.0}$, $\mathrm{Fe}_{74.25} \mathrm{~B}_{14.85} \mathrm{Si}_{9.9} \mathrm{Nb}_{1}, \quad \mathrm{Fe}_{36} \mathrm{Co}_{36} \mathrm{~B}_{19.2} \mathrm{Si}_{4.8} \mathrm{Nb}_{4}$ and 


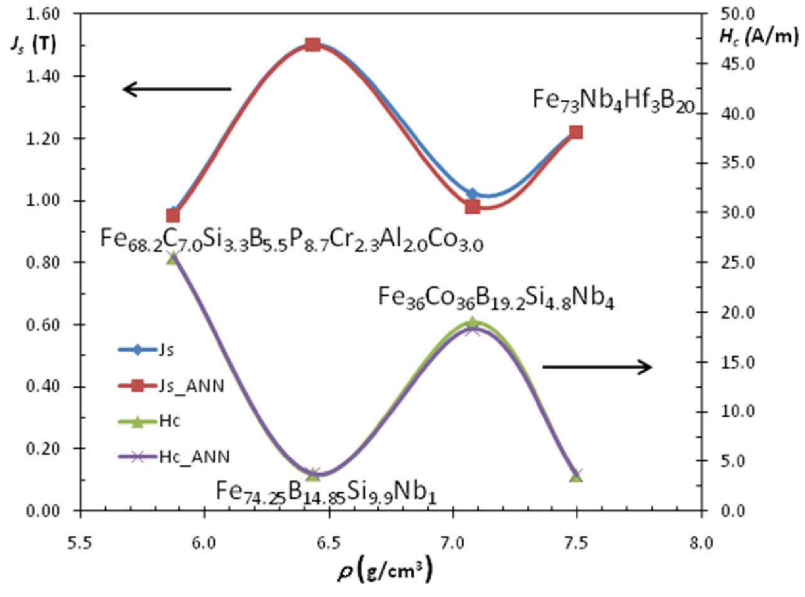

Fig. 2. Comparison of predicted and measured $J_{\mathrm{s}}$ and $H_{\mathrm{c}}$ for untrained data.
$\mathrm{Fe}_{73} \mathrm{Nb}_{4} \mathrm{Hf}_{3} \mathrm{~B}_{20}$ magnetic bulk glassy alloys which are not included to training data. The correlation is approximately found to be $99 \%$.

The proposed method has some inherent limitations which make it not a general solution. The trained neural network is based on a specific set of chemical composition of magnetic bulk amorphous alloys. For very different chemical compositions, a series of experiments would have to be performed again to obtain input vectors for a new ANN or the proposed ANN training. If the ANN input vectors could include the GFA and magnetic performance information and of new bulk glassy alloys, many more experimental data would have to be done to meet the accuracy requirements for a more general solution. However, since the neural model presented in this work has accuracy and requires no tremendous computational efforts and less background information about the bulk glassy alloys, it can be used to predict more accurately and easily the GFA and magnetic values of these alloys.

Predicted and measured the GFA and magnetic parameters for alloys used as training data.

TABLE

\begin{tabular}{|c|c|c|c|c|c|c|c|c|c|c|}
\hline Magnetic alloy composition & $\begin{array}{l}T_{\mathrm{g}} \\
{[\mathrm{K}]}\end{array}$ & $T_{\mathrm{g}_{[\mathrm{ANN}}}$ & $\begin{array}{l}T_{x} \\
{[\mathrm{~K}]}\end{array}$ & $T_{x} T_{[\mathrm{K}]}^{\mathrm{ANN}}$ & $T_{\text {rg }}$ & $T_{\text {rg_ANN }}$ & $\begin{array}{c}J_{\mathrm{s}} \\
{[\mathrm{T}]}\end{array}$ & $\begin{array}{c}J_{\mathrm{S}}{ }_{[\mathrm{TNN}} \\
{[\mathrm{T}]}\end{array}$ & $\begin{array}{c}H_{\mathrm{c}} \\
{[\mathrm{A} / \mathrm{m}]}\end{array}$ & $\begin{array}{c}H_{\mathrm{c}}{ } \mathrm{ANN} \\
{[\mathrm{A} / \mathrm{m}]}\end{array}$ \\
\hline $\mathrm{Fe}_{72} \mathrm{~B}_{22} \mathrm{Y}_{4} \mathrm{Ti}_{2}$ & 841.65 & 845.75 & 914.35 & 914.95 & 0.593 & 0.596 & 1.022 & 1.022 & 15.92 & 19.72 \\
\hline $\mathrm{Fe}_{76} \mathrm{Si}_{9} \mathrm{~B}_{10} \mathrm{P}_{5}$ & 780 & 778 & 832 & 830 & 0.620 & 0.600 & 1.51 & 1.50 & 0.8 & 0.78 \\
\hline $\mathrm{Fe}_{60} \mathrm{Co}_{10} \mathrm{Hf}_{5} \mathrm{Mo}_{7} \mathrm{~B}_{15} \mathrm{Y}_{3}$ & 879 & 877 & 943 & 942 & 0.594 & 0.597 & 0.533 & 0.622 & 79.58 & 79.67 \\
\hline $\mathrm{Fe}_{36} \mathrm{Co}_{36} \mathrm{~B}_{19.2} \mathrm{Si}_{4.8} \mathrm{Nb}_{4}$ & 817 & 820 & 856 & 862 & 0.601 & 0.593 & 1.02 & 0.99 & 19.02 & 18.23 \\
\hline $\mathrm{Fe}_{72} \mathrm{~B}_{22} \mathrm{Y}_{6}$ & 898.55 & 881.76 & 948.75 & 950.86 & 0.636 & 0.630 & 1.571 & 1.520 & 15.92 & 14.50 \\
\hline $\mathrm{Fe}_{66} \mathrm{~W}_{6} \mathrm{Y}_{6} \mathrm{~B}_{22}$ & 897 & 886 & 981 & 976 & 0.599 & 0.601 & 0.64 & 0.64 & 2 & 2 \\
\hline $\mathrm{Fe}_{70} \mathrm{Nb}_{4} \mathrm{Hf}_{3} \mathrm{~B}_{20} \mathrm{Y}_{3}$ & 850 & 853 & 924 & 916 & 0.592 & 0.591 & 1.05 & 1.04 & 2.1 & 1.9 \\
\hline
\end{tabular}

[6] H.W. Chang, Y.C. Huang, C.W. Chang, C.H. Chiu, W.C. Chang, J. Alloys Comp. 462, 68 (2008).

\section{Conclusion}

The ANN has been successfully applied for the prediction of the GFA parameters and magnetic properties of bulk glassy alloys. The results are found to be in very good agreement with previously reported data in literature. The developed ANN model can be used for the prediction of GFA parameters and magnetic properties of bulk glassy alloys.

\section{Acknowledgments}

This work was supported by the Commission of Scientific Research projects of Uludag University, project number $\operatorname{UAP}(\mathrm{F})-2010 / 19$.

\section{References}

[1] C. Suryanarayana, I. Seki, A. Inoue, J. Non.-Cryst. Solids 355, 355 (2009).

[2] A. Inoue, T. Zhang, H. Koshiba, J. Appl. Phys. 83, 6326 (1998).

[3] I. Kucuk, J. Magn. Magn. Mater. 305, 423 (2006).

[4] N. Kucuk, Ann. Nucl. Energy 35, 1787 (2008).

[5] Z. Longa, Y. Shao, G. Xie, P. Zhang, B. Shen, A. Inoue, J. Alloys Comp. 462, 52 (2008).
[7] F. Liu, S. Pang, R. Li, T. Zhang, J. Alloys Comp. 483, 613 (2009).

[8] B. Shen, C. Chang, Z. Zhang, A. Inoue, J. Appl. Phys. 102, 023515 (2007).

[9] B. Shen, M. Akiba, A. Inoue, Appl. Phys. Lett. 88, 131907 (2006).

[10] A. Makino, T. Kubota, C. Chang, M. Makabe, A. Inoue, J. Magn. Magn. Mater. 320, 2499 (2008).

[11] B. Shen, C. Chang, A. Inoue, Intermetallics 15, 9 (2007).

[12] H.X. Li, H.Y. Jung, S. Yi, J. Magn. Magn. Mater. 320, 241 (2008).

[13] J.M. Barandiaran, J. Bezanilla, H.A. Davies, P. Pawlik, Sensor. Actuat. A-Phys. 129, 50 (2006).

[14] S.F. Guo, Z.Y. Wu, L. Liu, J. Alloys Comp. 468, 54 (2009).

[15] H.W. Chang, Y.C. Huang, C.W. Chang, C.C. Hsieh, W.C. Chang, J. Alloys Comp. 472, 166 (2009).

[16] X.M. Huang, C.T. Chang, Z.Y. Chang, A. Inoue, J.Z. Jiang, Matter. Sci. Eng. A-Struct. 527, 1952 (2010).

[17] S.F. Guo, Z.Y. Wu, L. Liu, J. Alloys Comp. 468, 54 (2009). 